\title{
Knowledge and Attitude Towards Zoonoses among Animal Health Workers and Livestock Keepers in Arusha and Tanga, Tanzania
}

\author{
EMANUEL S. SWAI ${ }^{6 *}$, LUUK SCHOONMAN, and CHRIS J. DABORN \\ Veterinary Investigation Centre, P.O. Box 1068, Arusha, Tanzania \\ Tanga Dairy Trust, P.O. Box 1720, Tanga, Tanzania \\ Tropical Veterinary Services, P.O. Box 266 Karatu, Tanzania
}

\begin{abstract}
Zoonoses are infections naturally transmitted between vertebrate animals and humans. An exploratory questionnaire-based survey of animal health workers $(n=36)$ and livestock keepers $(n=43)$ was carried out from April 2001 to March 2002 in Tanga and Arusha regions, northern Tanzania, to assess local knowledge, attitudes and public awareness for animal zoonoses. A combination of closed and open-ended questions, focus group discussions and ranking techniques were employed to gather information on perceptions concerning the type of zoonotic diseases prevalent in the study area, level of risk, mode of transmission and methods of preventing disease transmission from animals to humans. The results demonstrated that rabies, tuberculosis and anthrax were considered the three most common zoonotic diseases. Sharing living accommodation with animals, consumption of un-treated livestock products (i.e. milk, meat or eggs) and attending to parturition were perceived as routes of transmission. Knowledge about zoonosis was higher in smallholder dairy (92\%; 33/36) than traditional livestock keepers $(P<0.05)$. On the contrary, the perceived risk of contracting a zoonosis was significantly higher in traditional livestock $(86 \% ; 6 / 7)$ than smallholder dairy keepers $(P<0.05)$. Stratification of the risk of zoonosis by farm location revealed that rural farms $(85 \% ; 7 / 8)$ were considered significantly at a higher risk when compared to peri or urban located farms $(P<0.05)$. Most of the respondents stated cooking of meat or boiling of milk as a way to prevent transmission. However, there was a significant difference in the perception of the risk posed by contact with potentially infected animals /or animal products with animal health workers having a much higher level of perception compared to livestock keepers. These results suggest that in the Tanga and Arusha, Tanzania, patchy awareness and knowledge of zoonoses, combined with food consumption habits and poor animal husbandry are likely to expose respondents to an increased risk of contracting zoonoses. Public health promotion on education and inter-disciplinary one-health collaboration between vets, public health practitioners and policy makers should result in a more efficient and effective joint approach to the diagnosis and control of zoonoses in Tanzania.
\end{abstract}

Key words: knowledge, perception, risk, transmission, control, zoonoses, Tanzania

\section{Introduction}

A zoonosis is any infectious disease that can be transmitted from animals, both wild and domestic, to humans (Coleman, 2002; WHO/FAO/OIE, 2004). Brucellosis, rabies, human African trypanosomiasis, bovine tuberculosos (BTB), cysticercosis, echinococcosis and anthrax, are listed as seven endemic zoonoses of concern (WHO, 2006). The majority of pathogenic species causing disease in humans are zoonotic - being estimated at $>60 \%$ of all human diseases (Morse, 1995; Palmer \& Soulby, 1998; Murphy, 1998). Zoonoses are also considered to be twice as likely to be associated with emerging diseases as non-zoonoses (Taylor et al., 2001). The

\footnotetext{
* Correspondence: Dr. Emmanuel E. Swai: E-mail: esswai@ gmail.com
}

emergence and re-emergence of zoonoses and their potentially disastrous impact on human health is a growing concern around the globe (Woolhouse \& Gowtage-Sequeria, 2005). In developing countries they constitute an important threat to human health (Wastling et al., 1999). Zoonotic diseases have both direct and indirect effects on livestock health and production (Smits \& Cutler, 2004). Indirect effects occur as a result of the risk of human disease, the economic impact on livestock producers through barriers to trade, the costs associated with control programmes, the increased cost of marketing produce to ensure it is safe for human consumption and the loss of markets because of decreased consumer confidence (McDermott \& Arimi, 2002; Perry et al., 2002).

The increase in urban and peri-urban livestock production furthermore poses a risk of 
introducing zoonoses that were formerly regarded as rural diseases to urban areas (Mahy \& Brown, 2000; Perry et al., 2002). Different management practices and environmental circumstances in traditional and smallholder livestock keeping systems in rural and (peri) urban areas can influence the risk of zoonoses (Wastling et al., 1999; Omudu \& Amuta, 2007). These practices, which could reduce or increase the risk of zoonoses, in the various livestock keeping systems and to the public as whole, will depend on awareness, perceptions, knowledge and attitude to zoonoses (Shirima et al., 2003; John et al., 2008). This level of awareness and knowledge might be different in the traditional system where cattle have been kept for generations and the smallholder system, which is relatively new and where only some of the dairy farmers have had a tradition of cattle keeping. Certain occupations have a higher risk of contracting zoonoses (Schelling et al., 2003; Swai \& Schoonman, 2009; Kramer, 2009). This is clearly the case where the disease is transmitted through direct contact with infected animals or infected animal materials. Livestock workers, veterinarians, abattoir workers, laboratory workers and people handling raw livestock products belong to these at-risk groups (McDermott \& Arimi, 2002). The objective of this study was to assess the level of awareness, local knowledge and management practices of the different risk groups in the study areas. The intention is that the baseline information generated will facilitate the development of effective and joint veterinary-medical policies and guidelines for controlling these zoonoses.

\section{Subjects and Methods}

\section{Study area and population}

This exploratory field study was conducted in and around Arusha (03'16- 03'20S and 36'37- 36'50 E) and Tanga (4'21-6'24 S and 36'11 - 38'26 E) cities. At the time of the last national census, in 2002, approximately 222,600 and 244,000 people lived in Tanga and Arusha municipality respectively, and the human population was growing at $2.9 \%$ year (www.tanzania.go.tz/census/ tables.htm). Arusha, however, is more urbanized, with $96 \%$ of the population living in urban areas compared to $74 \%$ in Tanga. Urban and peri-urban dairy systems in both cities are quite similar, although the numbers for most types of livestock are higher in Arusha. Tanga has a hot humid coastal climate, whereas Arusha has a cooler highlands climate, which is semi-arid close to the mountains and arid in the plains.

\section{Study design and data collection}

A semi-structured open-ended questionnaire was developed to assess perceptions, knowledge and attitudes toward zoonoses. The focus of the questionnaire was on animal health workers (in Tanga) and livestock keepers (Arusha and Tanga) knowledge considered important for identification and perception of the zoonoses. With respect to awareness, key information asked included listing and ranking diseases transmitted from animals to humans. Information was sought on views of how disease is introduced into a herd, the most at-risk animal or product as far as zoonoses is concerned and the associated signs of disease. A key question included an understanding of the zoonotic disease signs, protective measures taken before and after slaughter, pre-treatment of livestock products (meat, milk, blood) before consumption i.e. boiling milk, cooking meat etc and handling practices employed when attending cases of sudden death in animals, aborted foetus or retained placentas. Information was also sought on knowledge of the risks posed by animals and their products and the transmission routes. Respondents were asked to rank the risk to humans of contracting particular zoonoses and finally data were collected on the risk of zoonoses between localities i.e. urban, peri-urban and rural. A complete list of the question asked is given in Table 2. The study was conducted during the period of April 2001 to March 2002.

\section{Data analysis}

The data collected on the questionnaires and from the focus group discussion were stored and analyzed using version 6.04 of the Epi Info software package (Centers for Disease Control and Prevention, Atlanta, GA). The relationships between dependent and various independent factors were explored in $\mathrm{D}^{2}$ tests. A P-value of 0.05 was considered indicative of a statistically significant difference.

\section{Results}

\section{Descriptive statistics}

In total, 36 animal health workers, 7 traditional livestock keepers, 6 pig keepers and 30 smallholders dairy farmers participated in the questionnaire (Table 1). Based on the location of the interviewees, $48.8 \%, 32.5 \%$ and $18.6 \%$ were classified as being urban, peri-urban and rural residents, respectively. All pig keepers were Tanga urban residents. 
Table 1: The proportions of respondents in each category of each factor investigated during the study

\begin{tabular}{llll}
\hline \multirow{2}{*}{ Factor } & Category & \multicolumn{2}{l}{ Number of respondents $(\boldsymbol{n}, \boldsymbol{\%})$} \\
\cline { 3 - 3 } & & Arusha & Tanga \\
\hline \multirow{2}{*}{ Farming system } & Smallholders & $18(81.8)$ & $12(57.1)$ \\
& Traditional & $4(18.2)$ & $3(14.3)$ \\
\multirow{2}{*}{ Location } & Pig keepers & - & $6(28.6)$ \\
& Urban & $15(68.2)$ & $6(28.6)$ \\
\multirow{2}{*}{ Targeted group } & Peri-urban & $6(27.3)$ & $8(36.3)$ \\
& Rural & $1(4.5)$ & $7(33.3)$ \\
& Livestock keepers & $22(100)$ & $21(100)$ \\
\hline
\end{tabular}

Table 2: Zoonotic diseases and their relative frequencies as perceived by respondents

\begin{tabular}{|c|c|c|c|c|}
\hline \multirow{2}{*}{ Parameter } & \multicolumn{4}{|l|}{ Disease type } \\
\hline & $\operatorname{Anthrax}(n, \%)$ & TB $(n, \%)$ & Rabies (n, \%) & $\mathrm{CB}(\mathrm{n}, \%)$ \\
\hline \multicolumn{5}{|l|}{ Arusha, $(n=12)$} \\
\hline Number of respondents & $11(91.6)$ & $4(33.3)$ & $5(41.6)$ & $1(8.3)$ \\
\hline Average of mentions $($ mean $\pm \mathrm{SD})$ & $3.8 \pm 0.87$ & $2.4 \pm 0.72$ & $2.9 \pm 0.16$ & $1.3 \pm 0.16$ \\
\hline Range & $1-6$ & $1-6$ & $1-6$ & $1-4$ \\
\hline \multicolumn{5}{|l|}{ Tanga, $(n=12)$} \\
\hline Number of respondents & $4(33.3)$ & $8(66.6)$ & $6(50)$ & $2(16.6)$ \\
\hline Average of mentions $($ mean \pm StdDev) & $1.9 \pm 0.72$ & $2.8 \pm 0.64$ & $2.1 \pm 0.19$ & $0.2 \pm 0.22$ \\
\hline Range & $1-5$ & $1-5$ & $1-5$ & $1-4$ \\
\hline Over all, $(n=24)$ & $15(62.5)$ & $12(50)$ & $11(45.8)$ & $3(12.5)$ \\
\hline
\end{tabular}

$\mathrm{TB}=$ Tuberculosis; $\mathrm{CB}=$ Cysticercus bovis

\section{Zoonotic diseases reported by respondents}

All respondents knew that there are certain diseases in their area which are zoonoses. Rabies, tuberculosis and anthrax were reported as the top three diseases (Table 2). Whereas rabies was identified as an important zoonosis by all respondents, anthrax was mentioned more often in Arusha than Tanga, (92\% and $33 \%$ respectively) which may relate to the fact that anthrax cases are rarely experienced in Tanga. Tuberculosis was mentioned by $50 \%$ of all the respondents, equally in Arusha and Tanga. Notably, brucellosis and tapeworms (CB) were mentioned by only $17 \%$ of the respondents.

\section{Risk and knowledge toward zoonoses}

95\% of the respondents, (both livestock keepers and animal health workers) indicated sharing their house with animals, consumption of animal products, milk or meat or blood, as the primary route for transmission of diseases to humans. Attending parturition, contact with placenta or intrauterine intervention was mentioned as a secondary route (Table 3). Intrauterine intervention was perceived by animal health workers to be a significantly more important route of transmission of disease to humans when compared to the perceptions of livestock keepers $(P<0.05)$.

Table 3: Perception of the risk of zoonoses from the various types of farm activities and eating habits

\begin{tabular}{lll}
\hline \multirow{2}{*}{ Actions/activities } & \multicolumn{2}{l}{ Level of risk perception } \\
\cline { 2 - 3 } & $\begin{array}{l}\text { Animal health workers } \\
(\mathbf{n = 3 6 )}\end{array}$ & Livestock keepers $(\mathbf{n}=\mathbf{4 1})$ \\
\hline Attending sick animals: & + & + \\
\hline Dealing with diarrhoeic calf & +++ & ++ \\
Assisting with birth in cow & +++ & + \\
Intrauterine treatment after abortion & +++ & ++ \\
Contact with placenta & +++ & + \\
Disposing off aborted fetus & & + \\
\hline Farm related activities: & + & +++ \\
Milking & +++ & + \\
Sleeping in the cattle banda & ++ & + \\
Cleaning cattle stable & & +
\end{tabular}




\begin{tabular}{|c|c|c|c|c|}
\hline \multirow[b]{2}{*}{ Actions/activities } & \multicolumn{4}{|c|}{ Level of risk perception } \\
\hline & $\begin{array}{l}\text { Animal } \\
(\mathrm{n}=36)\end{array}$ & health & workers & Livestock keepers $(n=41)$ \\
\hline Walking bare feet in the kraal & ++ & & & + \\
\hline Slaughtering livestock & ++ & & & ++ \\
\hline Skin-skin contact with animals & ++ & & & ++ \\
\hline Preparing skin & ++ & & & + \\
\hline Disposing off manure & + & & & + \\
\hline Cutting road side pasture & + & & & + \\
\hline \multicolumn{5}{|l|}{ Behavior/eating habits: } \\
\hline $\begin{array}{l}\text { Drinking shallow well water close to } \\
\text { kraal }\end{array}$ & ++ & & & ++ \\
\hline Drinking raw milk & +++ & & & +++ \\
\hline Drinking pasteurized milk & + & & & + \\
\hline Drinking un-pasteurized milk & ++ & & & +++ \\
\hline Drinking raw blood & +++ & & & +++ \\
\hline Eating raw meat & ++ & & & +++ \\
\hline Eating well cooked meat & + & & & + \\
\hline Eating raw egg & ++ & & & + \\
\hline
\end{tabular}

Direct transmission of rabies through dog bites was known to all respondents. Other routes of direct transmission, for example by aerosols or direct contact were rarely mentioned, other than in relation to anthrax. Of those who mentioned anthrax as an important zoonosis, only $27 \%$ suggested contact with the carcass as a way of transmission. Whereas $91 \%$ $(n=39 / 43)$ of the livestock keepers perceived certain animal diseases could infect humans, this level of awareness was significantly higher in animal health workers and smallholders dairy keepers compared to traditional livestock keepers $(P<0.05)$. Very few livestock keepers $(30 \%, 13 / 43)$ had adequate knowledge with respect to disease symptoms. Knowledge of zoonosis was higher in smallholder dairy keeper $(92 \% ; 33 / 36)$ than traditional livestock keeper $(P<0.05)$, but on the contrary, the perceived risk of zoonosis was significantly higher in traditional livestock $(86 \% ; 6 / 7)$ than small-scale dairy keepers $(P<0.05)$. Stratification of risk of zoonosis by farm/respondents (mainly livestock keepers) locations revealed that rural farms $(85 \%$; $7 / 8$ ) were considered to be at a significantly higher risk when compared to peri or urban located farms $(P<0.05)$.

\section{Avoidance of food-borne zoonosis}

Most of the respondents mentioned cooking of meat or boiling of milk as a way to reduce the risk of contracting a zoonotic infection and there was a significant difference between the animal health workers and livestock keepers interviewed $(P<$ $0.05)$. The main reason given for boiling milk was to prevent tuberculosis and the main reason for cooking meat was to prevent tapeworm infestations. Forty percent (17/43) of the respondents reported occasionally drinking raw milk, or drinking soured milk prepared without boiling. Some $16.3 \%$ (7/43) of the respondents, all traditional livestock keepers, reported eating raw meat or raw offals, such as kidneys, liver, abomasum and raw fat from the hump of a cow or tail of a sheep. Some of the traditional livestock keepers reported eating meat from animals which died of anthrax, but only after proper cooking with the addition of certain herbs. Raw blood was still consumed by $43 \%$ (3/7) of the traditional livestock keeper respondents and 30\% (11/36) of the respondents in the smallholder pig/ and dairy sector consumed cooked blood. Raw or undercooked beef, un-pasteurised cows' milk and undercooked eggs were considered the main source of zoonotic diseases to humans (Table 4). 
Table 4: Risk of contracting zoonoses from the various types of animal products

\begin{tabular}{lll}
\hline \multirow{2}{*}{ Animal products } & Level of risk perception \\
\cline { 2 - 3 } & Animal health workers $(\mathbf{n}=\mathbf{3 6})$ & Livestock keepers $(\mathbf{n}=\mathbf{4 3})$ \\
\hline Cows' milk & +++ & ++ \\
Goats' milk & + & + \\
Beef & +++ & ++ \\
Goat meat & ++ & + \\
Mutton & + & + \\
Pork & ++ & + \\
Chicken meat & + & + \\
Chicken eggs & ++ & + \\
Duck eggs & + & + \\
\hline$+++=>70 \%$ respondent say yes, $++=>50-<75 \%$ respondent say yes: $+=<50 \%$ respondents say yes.
\end{tabular}

\section{Discussion}

Consistent with other studies in Tanzania, this study has shown patchy awareness and poor knowledge of zoonoses by livestock keepers (Shirima et al., 2003; Kambarage et al., 2003; John et al., 2008). Most livestock keepers are aware of diseases such as rabies, anthrax, or tuberculosis as zoonoses, but the awareness of brucellosis, as a zoonosis is significantly lower.

Whereas most livestock keepers are aware of the risk involved through the consumption of animal products, such as milk and meat, very few are aware of the risk of direct transmission, for example by aerosols or direct contact. This low level of awareness is likely to expose them to an increased risk of contracting zoonoses, as they are unlikely to take proper precautions or use protective clothing when dealing with abortions or calves with diarrhoea and during on-farm activities like milking, cleaning the cowshed or slaughtering cattle. Although livestock keepers might be aware of the risk of consuming raw milk or meat the habit of consuming raw milk, raw blood or raw or undercooked meat is, however, still common practice, especially among rural communities (Kambarage et al., 2003; Shirima et al., 2003). Not only livestock keepers, but also veterinary field staff and staff in health facilities, have a low awareness and poor knowledge of zoonoses. This shows that the emergency preparedness for such an epidemic zoonosis is low. Zoonoses are not part of routine differential diagnosis or of the advisory package to livestock keepers. Similarly, zoonoses like brucellosis and leptospirosis are not part of the differential diagnosis and testing routines in human health facilities, and consequently the diseases may be under-reported and proper treatment may not be given (John et al., 2008). Limited knowledge at these levels is due to the general lack of data on zoonoses in Tanzania and inadequate communication between veterinary and human health care professionals (Cripps, 2000).

In conclusion, the results from this and other studies in Tanzania suggest that zoonoses can pose a significant health risk to the population and that, in some cases, the level of risk has been grossly underestimated. The high prevalence of HIV in Tanzania further increases the threat posed by zoonotic infections, most notably tuberculosis. Despite the risk posed, awareness and knowledge of zoonoses is low in Tanzania. Local knowledge in both, the traditional and smallholder livestock keeping system is limited to a restricted number of zoonoses inclusive of anthrax, rabies and tuberculosis. An important finding is that the knowledge and awareness of the risk of infection by zoonoses through direct contact is lacking. It also appears from the study that traditional cattle keepers, who have been keeping cattle for several generations, are not more knowledgeable on zoonoses when compared with smallholder farmers. This limited knowledge and awareness of zoonoses, involves not only livestock keepers, but also veterinary field staff and staff at health facilities.

Much can be done by education and training to increase the knowledge and skills of different health professionals, and for raising awareness by facilitating communication and 
inter-disciplinary collaboration on research and/or sharing of information between veterinary, public health, agricultural personnel and policy makers (Coulibaly \& Yameogo, 2000). This can be used to guide the development of a coordinated, efficient and effective one health approach to the diagnosis, treatment and prevention of zoonotic diseases.

\section{Acknowledgements}

The authors are grateful to all livestock keepers and animal health workers who took part in this study for their consent and cooperation. Thanks are extended to the Director of Veterinary Service, Tanzania for permission to publish this work.

\section{Competing interest}

The authors declare that they have no competing interests.

Received 20 May 2010

Accepted 15 September 2010

\section{References}

Cleaveland, S., Laurenson, M.K. \& Taylor, L.H. (2001) Diseases of humans and their domestic mammals: pathogen characteristics, host range and the risk of emergence. Philosophical Transactions of the Royal Society of London Series B-Biological Sciences 356, 991-999.

Coleman, P.G. (2002) Zoonotic diseases and their impact on the poor. In: Perry, B.D., McDermott, J.J., Randolph, T.F. Sones, K.R. and Thornton, P.K. (2002). Investing in Animal Health Research to Alleviate Poverty. International Livestock Research Institute (ILRI), Nairobi, Kenya.

Coulibaly, N.D. \& Yameogo, K.R. (2000) Prevalence and control of zoonotic diseases: collaboration between public health workers and veterinarians in Burkina Faso. Acta Tropica 76, 53 - 57.

Cripps, P.J. (2000).Veterinary education, zoonoses and public health: a personal perspective. Acta Tropica 76, 77-80

Epi-info, (1996) Centre for Disease Control. version 6.04d, Epi-info, Atlanta, GA, USA and Geneva, Switzerland, pp 1-20.

John, K., Kazwala, R. \& Mfinanga, G.S. (2008) Knowledge of causes, clinical features and diagnosis of common zoonoses among medical practitioners in Tanzania. $B M C$ Infectious Diseases, 2 (8), 162.

Kambarage, D.M., Karimuribo, E.D., Kusiluka, L.J.M., Mdegela R.H. \& Kazwala R.R. (2003) Community Public Health Education in Tanzania: Challenges, Opportunities and the Way Forward. FAO, Expert consultation on community based Veterinary Public Health (VPH) systems, pp 55-63.

Kramer, L. (2009) Human toxoplasmosis and the role of veterinary clinicians. International Journal of Medical Sciences 6, 133-134.

Kunda, J., Fitzpatrick, J., Kazwala, R., French, N.P., Shirima, G., Macmillan, A., Kambarage, D., Bronsvoort, M. \& Cleaveland, S. (2007) Health-seeking behavior of human brucellosis cases in rural Tanzania. BMC Public Health 3, 315.

Livestock in Development (1999) Livestock in Poverty-Focused Development. Livestock in Development, Crewkerne, United Kingdom.

McDermott, J.J. \& Arimi, S.M. (2002) Brucellosis in sub-Saharan Africa: epidemiology, control and impact. Veterinary Microbiology 90, 111-134

Mfinanga, S.G., Morkve, O., Kazwala, R.R., Cleaveland, S., Sharp, J.M., Shirima, G. \& Nilsen, R. (2003) The role of livestock keeping in tuberculosis trends in Arusha, Tanzania. The International Journal of Tuberculosis and Lung Disease 7, 695-704

Morse, S.S. (1995) Factors in the emergence of infectious diseases. Emerging Infectious Diseases 1, 7-15.

Murphy, F.A. (1998) Emerging zoonoses. Emerging Infectious Diseases 3, 429-435.

Omudu, E.A. \& Amuta, E.U. (2007).Parasitology and urban livestock farming in Nigeria: prevalence of ova in faecal and soil samples and animal ectoparasites in Makurdi. Journal of South African Veterinary Association 78, 40-45.

Palmer, S.R., Soulby, E.J.L. \& Simpson, D.I.H. (1998) In: Zoonoses: Biology, Clinical Practice, and Public Health Control. New York: Oxford University Press; p. 266.

Perry, B.D., Randolf, T.F., McDermott, J.J., Sones, K.R. \& Thornton, P.K. (2002) In: Investing in Animal Health Research to Alleviate Poverty. International Livestock Research Institute (ILRI), Nairobi, Kenya, p. 133.

Schelling, E., Diguimbaye,C., Daoud, S., Nicolet, J., Boerlin, P., Tanner, M. \& J Zinsstag, J. (2003) 
Brucellosis and Q-fever seroprevalences of nomadic pastoralists and their livestock in Chad. Preventive Veterinary Medicine 61, 279-293.

Shirima, G.M., Fitzpatrick, J., Cleaveland, S., Kambarage, D.M., Kazwala, R.R., Kunda, J. \& French, N.P.(2003) Participatory Survey on Zoonoses Affecting Livestock Keeping Communities in Tanzania. Journal of Animal and Veterinary Advances 4, 253258.

Smits, H.L. \& Cutler, S.J. (2004) Contributions of biotechnology to the control and prevention of brucelliosis in Africa. African Journal of Biotechnology 3, 631-636.

Swai, E. S. \& Schoonman, L. (2009) Human brucellosis: seroprevalence and risk factors related to high risk groups occupational groups in Tanga, Municipality, Tanzania. Zoonoses and Public Health 56, 183-189.

Taylor, L. H., Latham, S. M. \& Woolhouse, M. E. J. (2001) Risk factors for human disease emergence. Philosophical Transactions of the Royal Society of London Series B-Biological Sciences 356,983-989.
URT (2002) Population and Household Census. United Republic of Tanzania., Available at: http: // www.tanzania.go.tz/cencus/table5. htm.2002; Accessed April, 2010

Wastling, J.M., Akanmori, B.D. \& Williams, D.J.L. (1999) Zoonoses in West Africa: impact and control. Parasitology Today 15, 309-311.

WHO (2006) The Control of Neglected Zoonotic Diseases: A Route to Poverty Alleviation. Geneva: Report of a joint WHO/DFID-AHP meeting with the participation of FAO and OIE, Geneva, 20-21 September, 2005

WHO/FAO/OIE. (2004) Report of the WHO/FAO/ OIE Joint Consultation on Emerging Zoonotic Diseases. 3-5 May 2004, Geneva, Switzerland. Food and Agriculture Organization of the United Nations (FAO), World Health Organization (WHO), and World Organisation for Animal Health (OIE).

Woolhouse, M.E.J. \& Gowtage-Sequeria, S. (2005) Host range and emerging and re-emerging pathogens. Emerging Infectious Diseases 11, 1842-1847. 